\title{
RESEARCH
}

Open Access

\section{Prognostic value of lymphovascular invasion in stage II colorectal cancer patients with an inadequate examination of lymph nodes}

Zhenyan Gao ${ }^{1+}$, Huihua $\mathrm{CaO}^{2+}$, Xiang Xu', Qing Wang ${ }^{1}$, Yugang Wu ${ }^{1 *}$ (D) and Qicheng $\mathrm{Lu}^{1 *}$

\begin{abstract}
Background: Lymphovascular invasion (LVI) is defined as the presence of cancer cells in lymphatics or blood vessels. This study aimed to evaluate the prognostic value of LVI in stage II colorectal cancer (CRC) patients with inadequate examination of lymph nodes (ELNs) and further combined LVI with the TNM staging system to determine the predictive efficacy for CRC prognosis. Adjuvant chemotherapy (ACT) was then evaluated for stage II CRC patients with LVI positivity (LVI+).

Methods: In order to avoid the effects of different ACT regimens, among 409 stage II patients, we chose 121 patients who received FOLFOX regimen and the 144 patients who did not receive ACT as the object of study. LVI was examined by hematoxylin-eosin (HE) staining. Kaplan-Meier analysis followed by a log-rank test was used to analyze survival rates. Univariate and multivariate analyses were performed using a Cox proportional hazards model. Harrell's concordance index (C-index) was used to evaluate the accuracy of different systems in predicting prognosis.

Results: The LVI+ status was significantly associated with $\mathrm{pT}$ stage, degree of differentiation, tumor stage, serum CEA and CA19-9 levels, perineural invasion (PNI), tumor budding (TB), and KRAS status. The 5-year overall survival (OS) rate of stage II patients with $<12$ ELNs and LVI+ was less than stage IIIA. Multivariate analyses showed that LVI, pT-stage, serum CEA and CA19-9 levels, PNI, TB, and KRAS status were significant prognostic factors for stage II patients with $<12$ ELNs. The 8th TNM staging system combined with LVI showed a higher C-index than the 8th TNM staging system alone (C-index, 0.895 vs. 0.833). Among patients with LVI+, the ACT group had a significantly higher 5-year OS and 5-year disease-free survival (DFS) than the surgery alone (SA) group (5-year OS, 66.7\% vs. $40.9 \%, P=0.004 ; 5$-year DFS, $64.1 \%$ vs. $36.3 \%, P=0.002$ ).

(Continued on next page)
\end{abstract}

\footnotetext{
*Correspondence: czyywyg89@163.com; czyyluqicheng123@163.com

Mini abstract: This study aimed to evaluate the prognostic value of LVI in

stage II CRC patients with inadequate ELNs and to further explore the prognostic efficacy of CRC.

'Zhenyan Gao and Huihua Cao contributed equally to this work.

'Department of General Surgery, The Third Affiliated Hospital of Soochow

University and The First People's Hospital of Changzhou, 185 Juqian Street,

Changzhou 213000, Jiangsu, China

Full list of author information is available at the end of the article
}

C C The Author(s). 2021 Open Access This article is licensed under a Creative Commons Attribution 4.0 International License, which permits use, sharing, adaptation, distribution and reproduction in any medium or format, as long as you give appropriate credit to the original author(s) and the source, provide a link to the Creative Commons licence, and indicate if changes were made. The images or other third party material in this article are included in the article's Creative Commons licence, unless indicated otherwise in a credit line to the material. If material is not included in the article's Creative Commons licence and your intended use is not permitted by statutory regulation or exceeds the permitted use, you will need to obtain permission directly from the copyright holder. To view a copy of this licence, visit http://creativecommons.org/licenses/by/4.0/ The Creative Commons Public Domain Dedication waiver (http://creativecommons.org/publicdomain/zero/1.0/) applies to the data made available in this article, unless otherwise stated in a credit line to the data. 
(Continued from previous page)

Conclusions: LVI is an independent prognostic risk factor for stage II CRC patients. Combining LVI with the 8th TNM staging system improved the predictive accuracy for CRC prognosis. ACT in stage II CRC patients with LVI+ is beneficial for survival.

Keywords: Lymphovascular invasion, Stage II colorectal cancer, Adjuvant chemotherapy, Survival, Prognostic factors

\section{Introduction}

Colorectal cancer (CRC) is the third most common malignancy and the fourth leading cause of tumorrelated deaths worldwide [1]. Although advances have been achieved in early detection and effective treatment, the survival rate of CRC is still poor [2]. Among all CRC patients, approximately one-third are diagnosed as stage II [3]. The National Comprehensive Cancer Network (NCCN) guidelines recommend adjuvant chemotherapy (ACT) for stage III and IV CRC [4]. For stage II CRC, the current guidelines recommend that ACT should be considered for patients at high risk for recurrence [5].

In addition, the current guidelines recommend that at least 12 lymph nodes (LNs) should be examined for nodal evolution [6]. Adequate $\mathrm{LN}$ retrieval from the specimen is essential to ensure accuracy in nodal staging [7]. An inadequate examination of lymph nodes (ELNs) may cause a false-negative result or a lower $\mathrm{pN}$ stage [8].

Lymphovascular invasion (LVI) is defined as the presence of cancer cells in lymphatics or blood vessels and is considered to be an early step in lymph node metastasis (Fig. 1) [1]. Many studies have reported that LVI positivity (LVI+) is a critical prognostic indicator in some cancers, including breast, bladder, and gastric cancers [9-11]. It has been reported that the presence of LVI in
CRC varies from 4.1 to $89.5 \%$ [12]. Currently, few studies have focused on LVI in stage II CRC with inadequate ELNs. Moreover, no study involving the combination of LVI and the TNM staging system in CRC patients has been published.

Tumor budding (TB) was defined as a single tumor cell or cluster comprising less than five cells at the invasive front [13]. At the International Tumor Budding Consensus Conference (ITBCC), it was clearly stated that tumor budding is an independent prognostic factor for CRC. The reason why tumor budding has not yet developed into routine clinical practice is because there is no consensus on the scoring method. This study used the methods proposed by ITBCC in clinical practice and studied the relationship between TB and the survival of patients with stage II CRC with ELNs. Cutoffs used were the following: low, 0-9 buds; and high, $\geq 10$ buds (Fig. 2a) [13]. Perineural invasion (PNI) is the process of nerve tumor infiltration, including tumor cells located in the three layers of the peripheral nerve sheath or adjacent to the nerve, and involving at least one third of its surroundings $[14,15]$. PNI has become a key pathological feature of many malignant tumors, including malignant tumors of the stomach, colon and rectum, pancreas, and biliary tract (Fig. 2b) [16-19]. At present, there is no consensus regarding the inclusion of PNI in

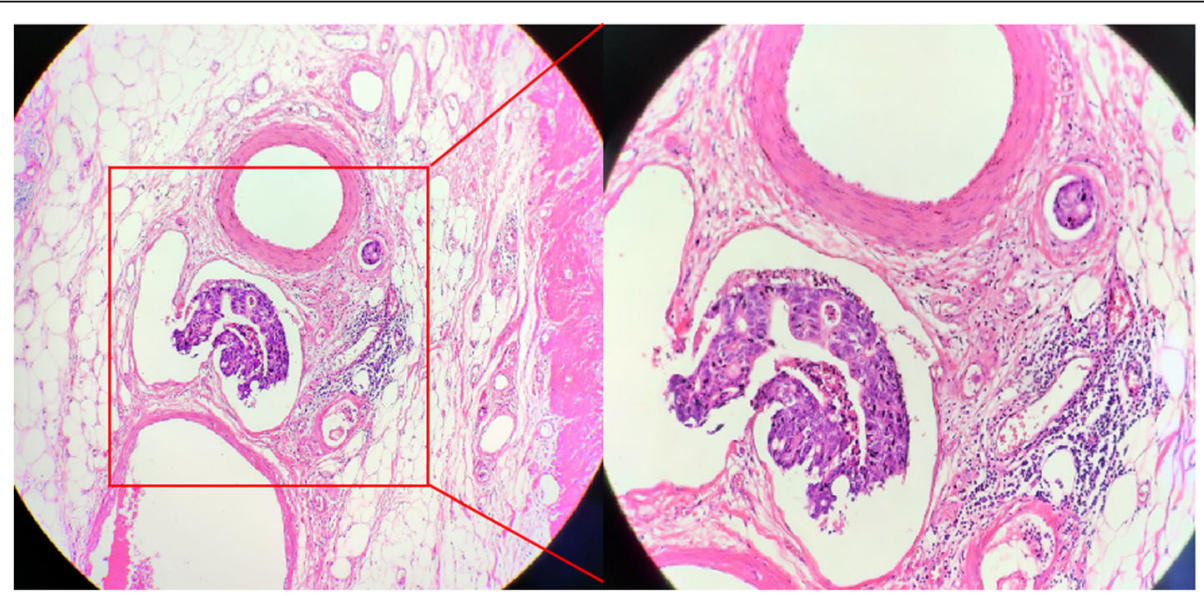

Fig. 1 An example of positive lymphovascular invasion (LVI), diagnosed by at least two experienced pathologists on H\&E examination. H\&E $(\times 100, \times 200)$ 


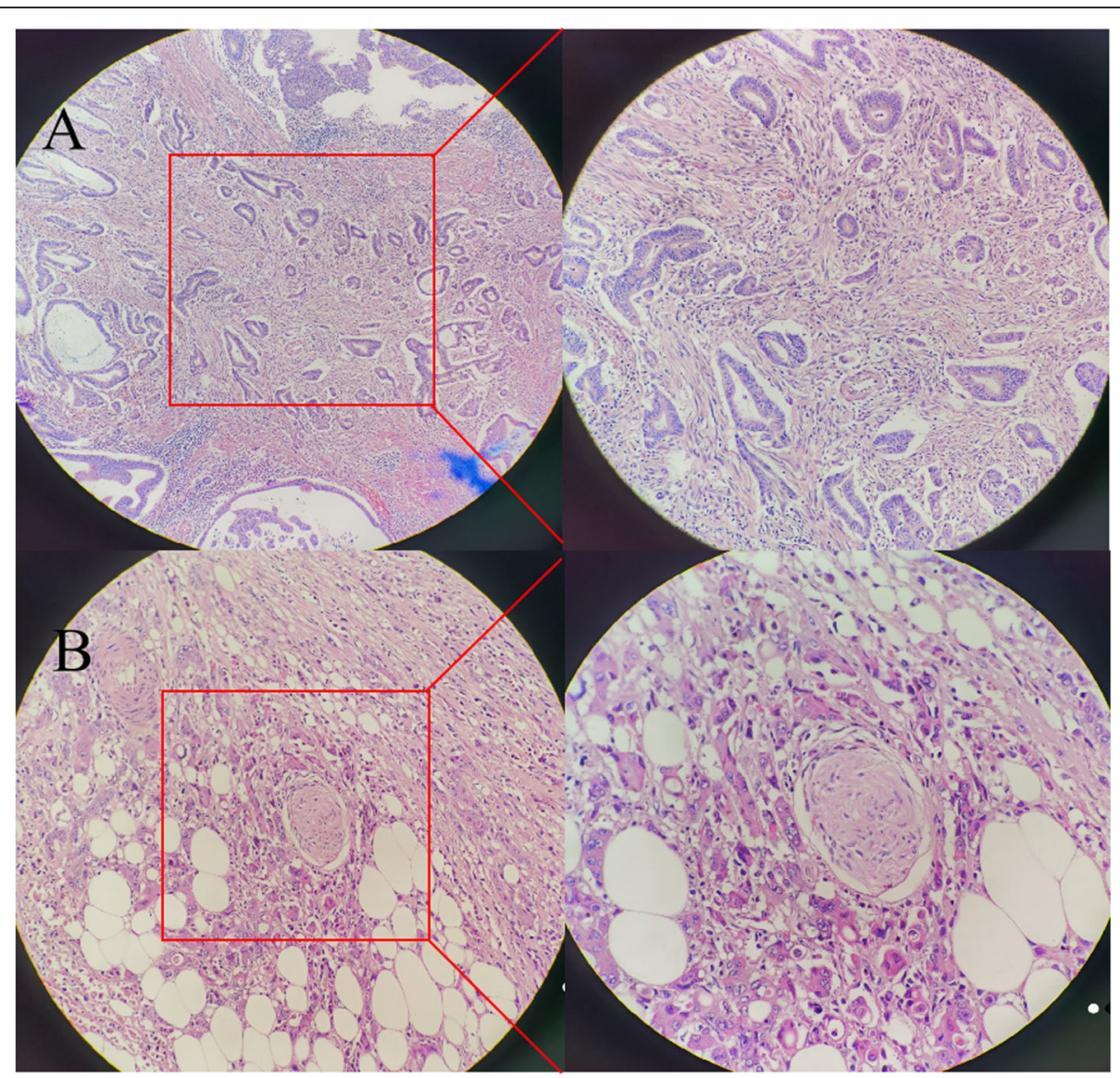

Fig. 2 Example of tumor budding (TB), H\&E $(\times 200, \times 400)($ a); an example of positive perineural invasion (PNI), H\&E $(\times 200, \times 400)(\mathbf{b})$

staging, although PNI has been proven to be a sign of poor survival in colorectal cancer.

We conducted the current study to evaluate the prognostic value of LVI in stage II CRC patients with inadequate ELNs and combined LVI with the tumor-node-metastasis (TNM) staging system to determine the predictive efficacy for CRC prognosis. ACT was then evaluated for stage II CRC patients with LVI+.

\section{Materials and methods}

\section{Patients}

We retrospectively examined the clinicopathologic records of CRC patients who were treated at the Third Affiliated Hospital of Soochow University between February 2007 and February 2013. The inclusion criteria were as follows: adenocarcinoma confirmed by histopathology, curative resection with lymphadenectomy, no neoadjuvant chemoradiation, complete clinicopathologic records, absence of distant metastases. The exclusion criteria were as follows: received neoadjuvant chemoradiation, incomplete clinicopathologic records, lost to follow-up, distant metastases. CRC stage was classified according to the 8th edition of the American Joint Committee on Cancer (AJCC) TNM staging system. Follow-up was carried out by telephone calls, emails, and on-site visits. Informed written consent was obtained from all CRC patients. The study was approved by the Ethics Committee of the Third Affiliated Hospital of Soochow University.

\section{ACT regimens for stage II CRC patients}

After curative resection, some stage II CRC patients chose to receive ACT for further treatment. The ACT regimen was established by our clinicians based on the patient's general performance, clinicopathologic features, and operative factors. A 6-month oxaliplatin-based regimen (FOLFOX [5-fluorouracil with oxaliplatin] or CapeOx [capecitabine with oxaliplatin]) was recommended for stage II CRC patients. For those patients with a contraindication to oxaliplatin, a 6-month fluoropyrimidine-based regimen (5-FU/LV [5-fluorouracil/leucovorin] or 5-FU [5-fluorouracil]) was an acceptable alternative. 
Table 1 Clinicopathologic characteristics of CRC patients. One thousand four hundred and twenty CRC patients from February 2007 to February 2013 who met the inclusion criteria were analyzed in this study. The clinicopathologic characteristics of 1420 CRC patients and the 409 stage II patients are listed in Table 1. Of the 409 stage II patients, 145 patients (35.5\%) were LVI+ and 264 (64.5\%) were LVI-

\begin{tabular}{|c|c|c|}
\hline Parameters & $\begin{array}{l}\text { Overall patients } \\
n(\%)\end{array}$ & $\begin{array}{l}\text { Stage II patients } \\
n(\%)\end{array}$ \\
\hline \multicolumn{3}{|l|}{ Sex } \\
\hline Female & $598(42.1)$ & $169(41.3)$ \\
\hline Male & $822(57.9)$ & $240(58.7)$ \\
\hline \multicolumn{3}{|l|}{ Age (years) } \\
\hline$\leq 65$ & $669(47.1)$ & $198(48.4)$ \\
\hline$>65$ & $751(52.9)$ & $211(51.6)$ \\
\hline \multicolumn{3}{|l|}{ Tumor site } \\
\hline Colon & $846(59.6)$ & $217(53.1)$ \\
\hline Rectum & $574(40.4)$ & $192(46.9)$ \\
\hline \multicolumn{3}{|c|}{ Tumor size (cm) } \\
\hline$\leq 4$ & $688(48.5)$ & $209(51.1)$ \\
\hline$>4$ & $732(51.5)$ & $200(48.9)$ \\
\hline \multicolumn{3}{|c|}{ Lymphovascular invasion } \\
\hline Positive & $486(34.2)$ & $145(35.5)$ \\
\hline Negative & $934(65.8)$ & $264(64.5)$ \\
\hline \multicolumn{3}{|l|}{ T-stage } \\
\hline $\mathrm{T} 1$ & $233(16.4)$ & \\
\hline $\mathrm{T} 2$ & $393(27.7)$ & \\
\hline $\mathrm{T} 3$ & $457(32.2)$ & $218(53.3)$ \\
\hline T4 & $337(23.7)$ & $191(46.7)$ \\
\hline \multicolumn{3}{|l|}{ N-stage } \\
\hline No & $582(41.0)$ & $409(100.0)$ \\
\hline N1 & $498(35.1)$ & \\
\hline N2 & $340(23.9)$ & \\
\hline \multicolumn{3}{|c|}{ Differentiation degree } \\
\hline Well & $666(46.9)$ & $198(48.4)$ \\
\hline Moderate & $582(41.0)$ & $182(44.5)$ \\
\hline Poor & $172(12.1)$ & $29(7.1)$ \\
\hline \multicolumn{3}{|l|}{ CEA } \\
\hline$\leq 5 \mathrm{ng} / \mathrm{ml}$ & $836(58.9)$ & $243(59.4)$ \\
\hline$>5 \mathrm{ng} / \mathrm{ml}$ & $584(41.1)$ & $166(40.6)$ \\
\hline \multicolumn{3}{|l|}{ CA19-9 } \\
\hline$\leq 37 \mathrm{U} / \mathrm{ml}$ & $1106(77.9)$ & $322(78.7)$ \\
\hline$>37 \mathrm{U} / \mathrm{ml}$ & $314(22.1)$ & $87(21.3)$ \\
\hline \multicolumn{3}{|l|}{ Retrieved LN } \\
\hline$<12$ & $564(39.7)$ & $164(40.1)$ \\
\hline$\geq 12$ & $856(60.3)$ & $245(59.9)$ \\
\hline \multicolumn{3}{|l|}{ Treatment } \\
\hline $\mathrm{ACT}$ & $960(67.6)$ & $265(64.8)$ \\
\hline SA & $460(32.4)$ & $144(35.2)$ \\
\hline
\end{tabular}


Table 1 Clinicopathologic characteristics of CRC patients. One thousand four hundred and twenty CRC patients from February 2007 to February 2013 who met the inclusion criteria were analyzed in this study. The clinicopathologic characteristics of 1420 CRC patients and the 409 stage II patients are listed in Table 1. Of the 409 stage II patients, 145 patients (35.5\%) were LVI+ and 264 (64.5\%) were LVI- (Continued)

\begin{tabular}{|c|c|c|}
\hline Parameters & $\begin{array}{l}\text { Overall patients } \\
n(\%)\end{array}$ & $\begin{array}{l}\text { Stage II patients } \\
n(\%)\end{array}$ \\
\hline \multicolumn{3}{|l|}{ TNM stage } \\
\hline I & $173(12.2)$ & \\
\hline$\|$ & 409 (28.8) & \\
\hline$\| \mathrm{A}$ & $174(12.3)$ & \\
\hline$\| B$ & $121(8.5)$ & \\
\hline$\| C$ & $114(8.0)$ & \\
\hline III & $838(59.0)$ & \\
\hline$\| I I A$ & $324(22.8)$ & \\
\hline$\| \mathrm{II}$ & $287(20.2)$ & \\
\hline $\mathrm{IIIC}$ & $227(16.0)$ & \\
\hline \multicolumn{3}{|l|}{ KRAS status } \\
\hline Wild type & $975(68.7)$ & $248(60.6)$ \\
\hline Mutant type & 445 (31.3) & 161 (39.4) \\
\hline \multicolumn{3}{|l|}{ PNI } \\
\hline Positive & $276(19.4)$ & $90(22.0)$ \\
\hline Negative & 1144 (80.6) & $319(78.0)$ \\
\hline \multicolumn{3}{|l|}{ TB } \\
\hline Low & 995 (70.1) & 294 (71.9) \\
\hline High & 425 (29.9) & $115(28.1)$ \\
\hline
\end{tabular}

CRC Colorectal cancer; LN Lymph nodes; PNI Perineural invasion; TB Tumor budding

\section{Data collection and LVI examination}

Patient medical records were reviewed to obtain clinicopathologic data. Age, sex, tumor size, tumor location, LVI, TNM stage, degree of differentiation, ELNs, serum CEA and CA19-9 levels, perineural invasion, tumor budding, and KRAS status were recorded. Specimens were fixed in formalin, then cut into multiple slices. The histopathological examination was performed using a 5-mm-thick longitudinal whole tissue section. Slices were then embedded in paraffin and stained with hematoxylin-eosin (HE). All H\&E slides were evaluated by at least two experienced pathologists, who independently assessed LVI, TB, and PNI. Lymphovascular invasion (LVI) is defined as the presence of cancer cells in lymphatics or blood vessels [1]. Tumor budding (TB) was defined as a single tumor cell or cluster comprising less than five cells at the invasive front [13]. Perineural invasion (PNI) is the process of nerve tumor infiltration, including tumor cells located in the three layers of the peripheral nerve sheath or adjacent to the nerve, and involving at least one third of its surroundings [14, 15]. The Amplified Refractory Mutation System (ARMS) was used to detect KRAS mutations in colorectal cancer.

\section{Statistical analysis}

All analyses were performed using the SPSS (version 25.0 software; IBM, Chicago, IL, USA) and R software (version 3.0.0; www.r-project.org). Statistical significance was tested using Student's $t$-test and chisquared test. Univariate and multivariate analyses were performed using a Cox proportional hazards model. Kaplan-Meier analysis followed by a log-rank test was used to analyze survival rates. Harrell's concordance index (C-index) was used to evaluate the accuracy of different systems in predicting prognosis. All statistical analyses were two-sided, and a $P<0.05$ was considered statistically significant.

\section{Results}

Patient characteristics

One thousand four hundred and twenty CRC patients from February 2007 to February 2013 who met the inclusion criteria were evaluated in this study. The clinicopathologic characteristics of 1420 
Table 2 Occurrence of LVI in 265 stage II CRC patients. The incidence of LVI in stage II CRC patients is listed in Table 2 according to clinicopathologic characteristics. The LVI status was significantly associated with pT stage, degree of differentiation, tumor stage, serum CEA and CA19-9 levels, perineural invasion, tumor budding, and KRAS status. No significance existed in sex, age, tumor size, tumor site, and ELNs

\begin{tabular}{|c|c|c|c|c|}
\hline \multirow[t]{2}{*}{ Parameters } & \multirow{2}{*}{$\begin{array}{l}\text { LVI (+) } \\
n\end{array}$} & \multirow{2}{*}{$\begin{array}{l}\text { LVI (-) } \\
n\end{array}$} & \multirow[t]{2}{*}{$P$ value } & \multirow[t]{2}{*}{ LVI $(+)$ rate $(\%)$} \\
\hline & & & & \\
\hline Sex & & & 0.563 & \\
\hline Female & 43 & 65 & & 43/108 (39.8\%) \\
\hline Male & 57 & 100 & & 57/157 (36.3\%) \\
\hline Age (years) & & & 0.102 & \\
\hline$\leq 65$ & 54 & 72 & & $54 / 126$ (42.9\%) \\
\hline$>65$ & 46 & 93 & & 46/139 (33.1\%) \\
\hline Tumor site & & & 0.276 & \\
\hline Colon & 59 & 86 & & 59/145 (40.7\%) \\
\hline Rectum & 41 & 79 & & $41 / 120(34.2 \%)$ \\
\hline T-stage & & & $<0.001$ & \\
\hline T3 & 33 & 111 & & 33/144 (22.9\%) \\
\hline T4a & 31 & 34 & & $31 / 65$ (47.7\%) \\
\hline $\mathrm{T} 4 \mathrm{~b}$ & 36 & 20 & & $36 / 56(64.3 \%)$ \\
\hline Tumor size $(\mathrm{cm})$ & & & 0.186 & \\
\hline$\leq 4$ & 48 & 93 & & 48/141 (34.0\%) \\
\hline$>4$ & 52 & 72 & & $52 / 124$ (41.9\%) \\
\hline Differentiation degree & & & $<0.001$ & \\
\hline Well & 38 & 97 & & 38/135 (28.1\%) \\
\hline Moderate & 52 & 66 & & $52 / 118(44.1 \%)$ \\
\hline Poor & 10 & 2 & & 10/12 (83.3\%) \\
\hline CEA & & & $<0.001$ & \\
\hline$\leq 5 \mathrm{ng} / \mathrm{ml}$ & 28 & 133 & & 28/161 (17.4\%) \\
\hline$>5 \mathrm{ng} / \mathrm{ml}$ & 72 & 32 & & 72/104 (69.2\%) \\
\hline CA19-9 & & & $<0.001$ & \\
\hline$\leq 37 \mathrm{U} / \mathrm{ml}$ & 61 & 151 & & $61 / 212(28.8 \%)$ \\
\hline$>37 \mathrm{U} / \mathrm{ml}$ & 39 & 14 & & 39/53 (73.6\%) \\
\hline Retrieved LN & & & 0.062 & \\
\hline$<12$ & 48 & 60 & & 48/108 (44.4\%) \\
\hline$\geq 12$ & 52 & 105 & & 52/157 (33.1\%) \\
\hline Treatment & & & $<0.001$ & \\
\hline $\mathrm{ACT}$ & 78 & 43 & & 78/101 (64.5\%) \\
\hline SA & 22 & 122 & & $22 / 144$ (15.3\%) \\
\hline$\|$ & & & 0.023 & \\
\hline$\| \mathrm{A}$ & 37 & 76 & & $37 / 113$ (32.7\%) \\
\hline$\| \mathrm{B}$ & 34 & 44 & & $34 / 78(43.6 \%)$ \\
\hline$\| C$ & 39 & 35 & & 39/74 (52.7\%) \\
\hline KRAS status & & & $<0.001$ & \\
\hline Wild type & 39 & 121 & & $39 / 160$ (24.4\%) \\
\hline Mutant type & 61 & 44 & & 61/105 (58.1\%) \\
\hline
\end{tabular}


Table 2 Occurrence of LVI in 265 stage II CRC patients. The incidence of LVI in stage II CRC patients is listed in Table 2 according to clinicopathologic characteristics. The LVI status was significantly associated with pT stage, degree of differentiation, tumor stage, serum CEA and CA19-9 levels, perineural invasion, tumor budding, and KRAS status. No significance existed in sex, age, tumor size, tumor site, and ELNs (Continued)

\begin{tabular}{|c|c|c|c|c|}
\hline \multirow[t]{2}{*}{ Parameters } & LVI (+) & LVI (-) & $P$ value & $\mathrm{LVI}(+)$ rate $(\%)$ \\
\hline & $n$ & $n$ & & \\
\hline PNI & & & $<0.001$ & \\
\hline Negative & 66 & 141 & & 66/207 (31.9\%) \\
\hline Positive & 34 & 24 & & $34 / 58$ (58.6\%) \\
\hline TB & & & $<0.001$ & \\
\hline Low & 59 & 136 & & 59/195 (30.3\%) \\
\hline High & 41 & 29 & & $41 / 70$ (58.6\%) \\
\hline
\end{tabular}

CRC Colorectal cancer; LN Lymph nodes; LVI Lymphovascular invasion; PNI Perineural invasion; TB Tumor budding

Table 2. Occurrence of LVI in 265 stage II CRC patients

CRC patients are listed in Table 1 . Of all CRC patients, there were 822 males $(57.9 \%)$ and 598 females (42.1\%); $47.1 \%$ of patients were $\leq 65$ years of age. and $52.9 \%$ of patients were $>65$ years of age. The mean number of tumor size was $4.31 \pm 2.38$ for LVI+ group and $3.98 \pm 2.09$ for LVI- group. The number of stages I, II, and III patients were 173,
409 , and 838 , respectively. Of the 409 stage II patients, 144 patients did not receive ACT, 121 patients received FOLFOX regimen, 56 patients received CapeOx regimen, 48 patients received 5-FU/ $\mathrm{LV}$ regimen, and 40 received 5-FU regimen.

In order to avoid the effects of different ACT regimens, among 409 stage II patients, we chose 121

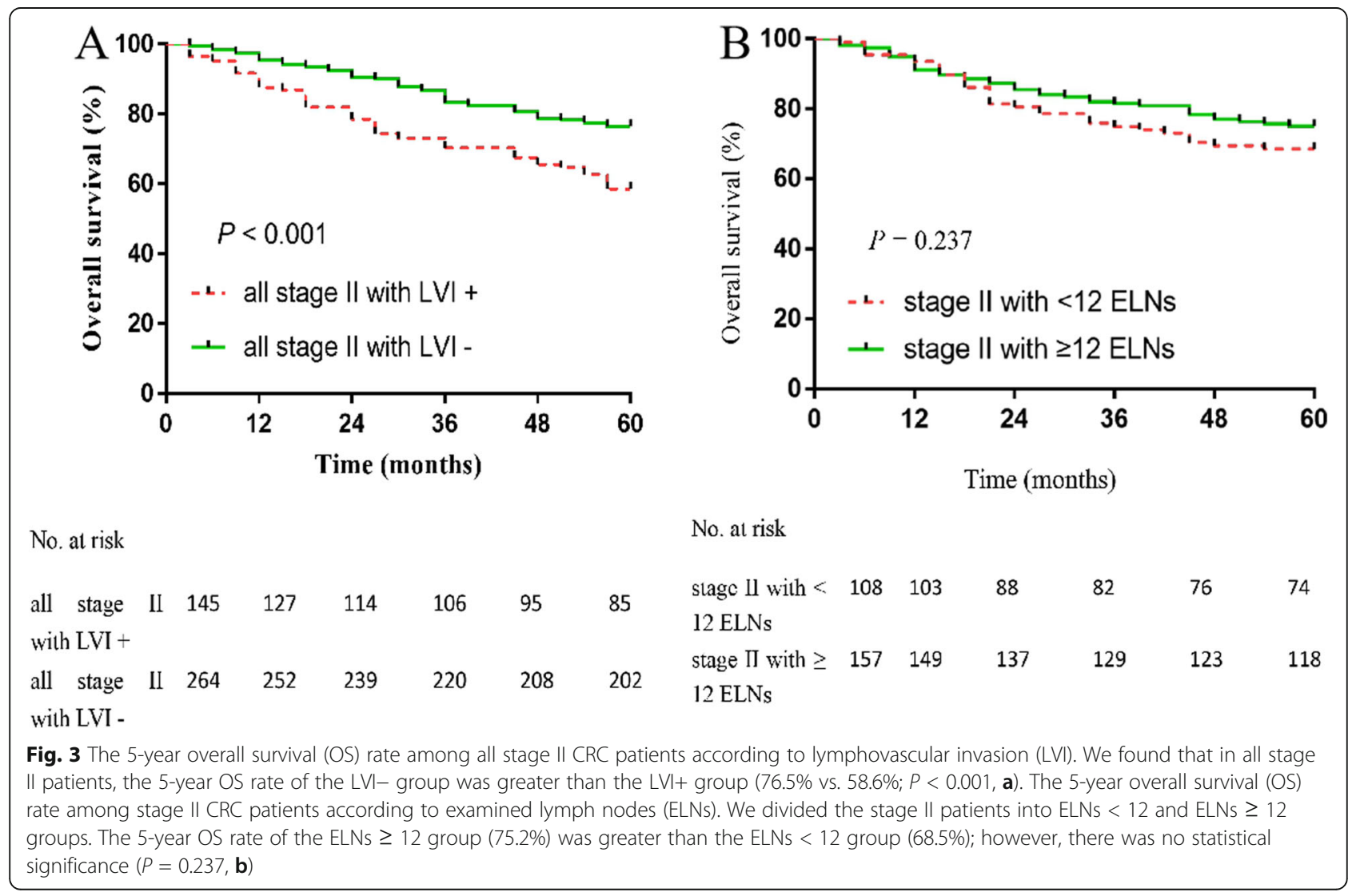




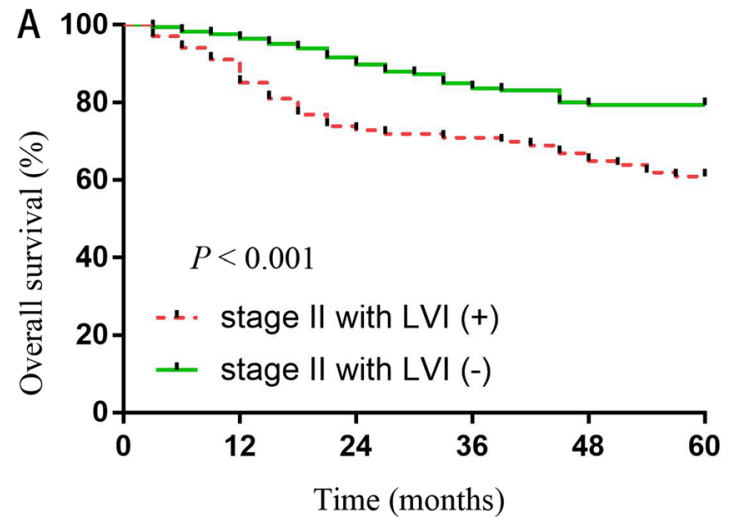

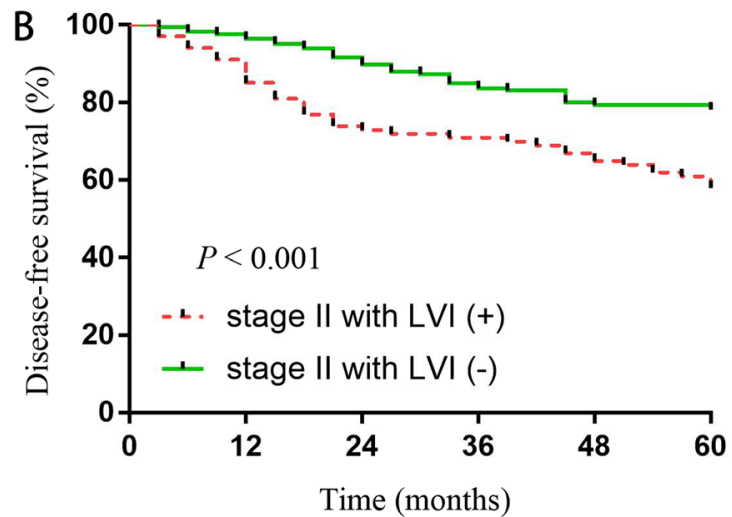

No. at risk

$\begin{array}{lllllll}\text { stage II LVI + } & 100 & 91 & 74 & 72 & 67 & 61\end{array}$

No. at risk

$\begin{array}{ccccccc}\text { stage II LVI + } & 100 & 91 & 74 & 72 & 67 & 61 \\ \text { stage II LVI - } & 165 & 161 & 151 & 138 & 132 & 131\end{array}$

$\begin{array}{llllll} & 165 & 161 & 151 & 140 & 132\end{array}$ (LVI). When dividing the stage II patients into LVI+ and LVI- groups, the 5-year OS rate of the LVI+ group was greater than LVI- (79.4\% Vs. 61.0\%, $P<0.001, \mathbf{a})$. The 5-year DFS rate of the LVI- group was greater than the LVI+ group (78.2\% vs. 58.0\%; $P<0.001, \mathbf{b})$

patients who received FOLFOX regimen and the 144 patients who did not receive ACT as the object of study. Finally, these 265 stage II patients were analyzed in this study whose clinicopathologic characteristics are listed in Table 1. One hundred patients (37.7\%) were LVI+ and 165 (62.3\%) were LVI-. We divided these stage II patients into ACT and surgery alone (SA) groups.

\section{Occurrence of LVI in stage II CRC patients}

As shown in Table 2, the incidence of LVI in 265 stage II CRC patients is listed based on clinicopathologic characteristics. The LVI status was significantly associated with pT stage, degree of differentiation, tumor stage, serum CEA and CA19-9 levels, perineural invasion, tumor budding, and KRAS status. The incidence of LVI in pT3, pT4a, and pT4b stages was $22.9 \%, 47.7 \%$, and $64.3 \%$, respectively. There was a statistically significant difference between LVI and pT stage. No significant difference existed with respect to sex, age, tumor size, tumor site, and ELNs.

\section{Overall survival of CRC patients}

We found that in all stage II patients, the 5-year OS rate of the LVI- group was greater than the LVI+ group (76.5\% vs. 58.6\%; $P<0.001$; Fig. 3a). We divided the 265 stage II patients into ELNs $<12$ and ELNs $\geq 12$ groups. The 5-year OS rate of the ELNs $\geq$ 12 group (75.2\%) was greater than the ELNs $<12$ group (68.5\%); however, there was no statistically significant difference (Fig. 3b). The 5-year OS rate of the LVI- group was greater than the LVI+ group (79.4\% vs. $61.0 \%$; $P<0.001$; Fig. 4a). The 5 -year DFS rate of the LVI- group was greater than the LVI+ group (78.2\% vs. 58.0\%; $P<0.001$; Fig. 4b). We further compared the OS rates among stage II patients with $\geq 12$ ELNs; stage II LVI- patients with < 12 ELNs; stage II LVI+ patients with < 12 ELNs; and stages IIIA, IIIB, and IIIC patients (Fig. 5). The 5-year OS rate of stage II LVI+ patients with $<12$ ELNs was $60.4 \%$, which is significantly less than stage II LVIpatients with $<12$ ELNs and stage II patients with $\geq$ 12 ELNs, respectively $(60.4 \%$ vs. $75 \%, P<0.001$; $60.4 \%$ vs. $75.2 \%, P<0.001)$; the 5 -year OS rate of stage II LVI+ patients with $<12$ ELNs was even lower than stage IIIA; however, there was no significant differences between the two groups $(P>0.05)$. No significant differences existed between stage II LVI+ patients with $<12$ ELNs and stages IIIA and IIIB patients $(60.4 \%$ vs. $65.7 \%$ vs. $54.3 \%, P=0.052)$. The 5-year OS rate of the TB low group was greater than the TB high group $(75.0 \%$ vs. $50.0 \% ; P=0.007$; Fig. 6a). The 5-year OS rate of the PNI - group was greater than the PNI + group $(74.2 \%$ vs. $42.1 \% ; P=$ 0.003; Fig. 6b).

\section{Univariate and multivariate analyses for the prognosis of stage II patients with $<12$ ELNs}

Owing to the specific characteristics of stage II patients with $<12$ ELNs, the prognostic factors were further analyzed. Univariate analyses showed that LVI, pT-stage, degree of differentiation, and CEA and CA19-9 levels were 


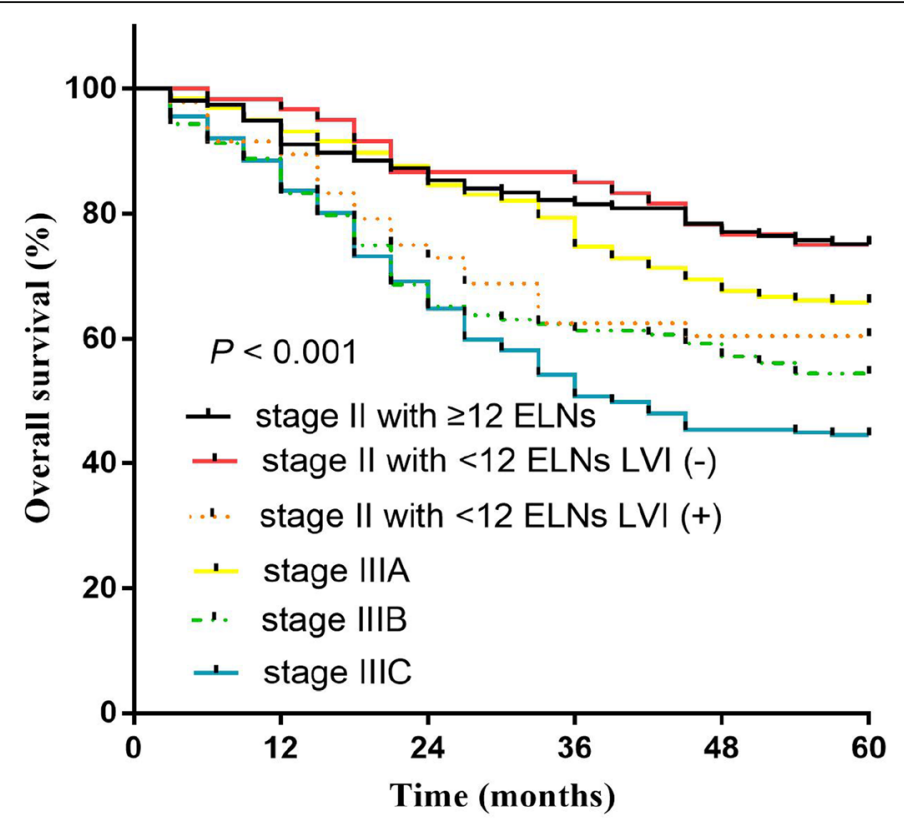

No. at risk

$\begin{array}{lcccccc}\begin{array}{l}\text { stage II with } \geq \\ \text { 12 ELNs }\end{array} & 149 & 137 & 129 & 123 & 118 \\ \begin{array}{l}\text { stage II with }< \\ \text { 12 ELNs LVI - }\end{array} & 59 & 55 & 52 & 47 & 45 \\ \text { stage II with < } & 48 & 44 & 36 & 33 & 30 & 29 \\ \text { 12 ELNs LVI + } & & & & & & \\ \text { stages IIIA } & 324 & 308 & 284 & 257 & 225 & 213 \\ \text { stages IIIB } & 287 & 255 & 197 & 179 & 170 & 156 \\ \text { stages IIIC } & 227 & 201 & 157 & 123 & 109 & 101\end{array}$

Fig. 5 The 5-year overall survival (OS) rates among the different groups. We compared the OS rate among stage II patients with $\geq 12$ ELNs; stage II LVI- patients with < $12 \mathrm{ELNs}$; stage II LVI+ patients with < $12 \mathrm{ELNs}$; and stages IIIA, IIIB, and IIIC patients. The 5-year OS rate of stage II LVI+ patients with $<12$ ELNs was $60.4 \%$, which is significantly lower than stage II LVI- patients with $<12$ ELNs and stage II patients with $\geq 12$ ELNs, respectively $(60.4 \%$ vs. $75 \%, P<0.001 ; 60.4 \%$ vs. $75.2 \%, P<0.001)$. No significance existed among stage II LVI+ patients with $<12$ ELNs and stages IIIA and IIIB (60.4\% vs. $65.7 \%$ vs. $54.3 \%, P=0.052)$

significant prognostic factors for stage II patients with < 12 ELNs; further multivariate analysis identified that LVI, pT-stage, degree of differentiation, CEA and CA199 levels, PNI, TB, and KRAS status were significant prognostic factors for stage II patients with $<12$ ELNs (all $P$ $<0.05$ ) (Table 3).

\section{Improvement of the 8th TNM staging system}

Because of the similarity in 5-year OS rates between stage II LVI+ patients with $<12$ ELNs and stages IIIA and IIIB patients, we combined LVI with the 8th TNM staging system. A comparison was made to estimate the prognostic value between the new system and the 8th
TNM staging system (Table 4). Stage II LVI+ patients with $<12$ ELNs were upgraded to stage III, while stage II LVI- patients with $<12$ ELNs remained stage II. The 8th TNM staging system combined with LVI had a higher $\mathrm{C}$-index than the 8th TNM staging system alone (C-index, 0.895 vs. 0.833), which indicates a better prognostic value for CRC patients.

\section{Relationship between LVI and ACT in stage II CRC patients}

In addition to analyzing OS, we also analyzed diseasefree survival (DFS), especially in stage II CRC patients. The 5-year DFS rate of the LVI- group was greater than the LVI+ group (78.2\% vs. $58.0 \% ; P<0.001$; Fig. 4 b). We 


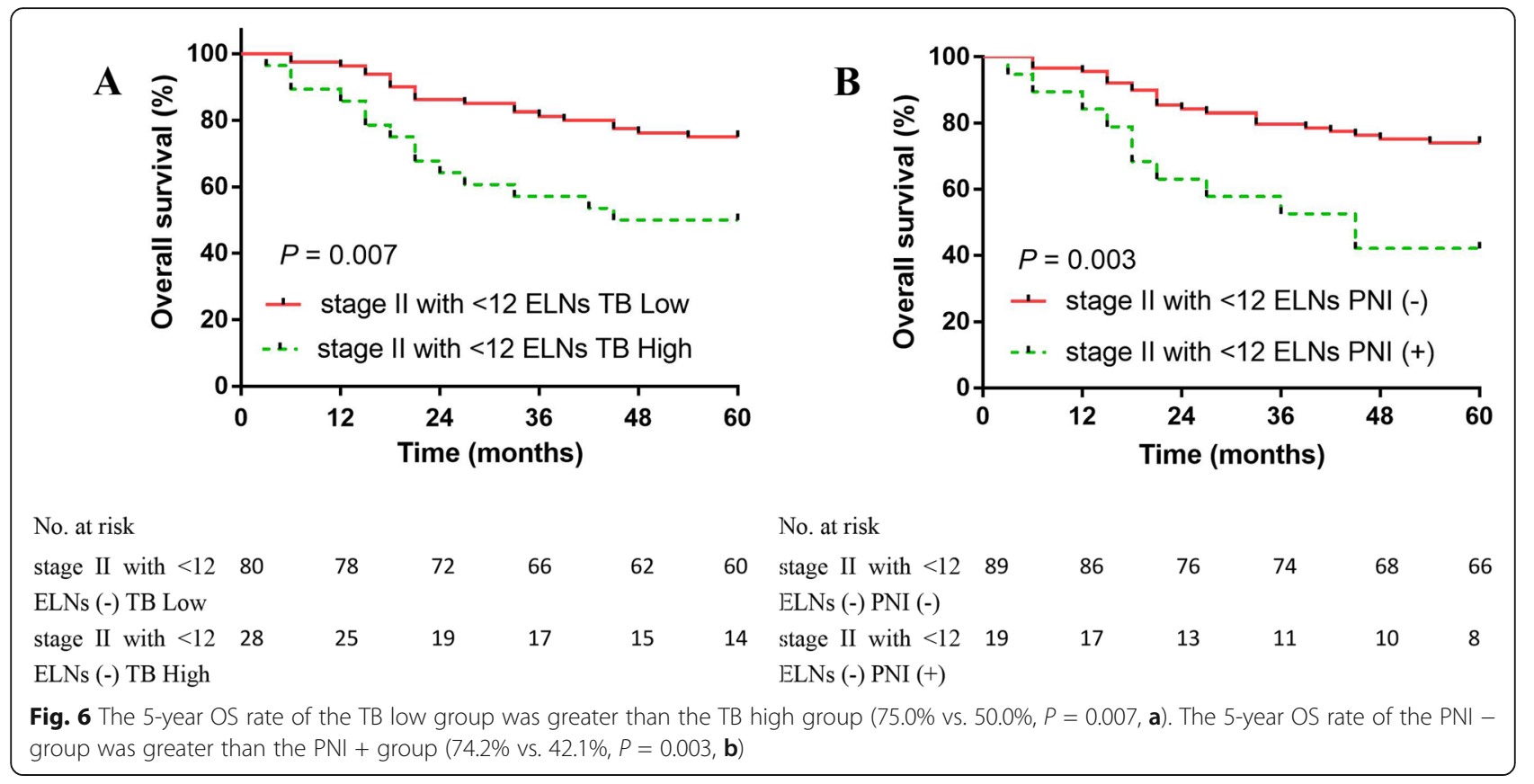

further divided the stage II CRC patients into ACT and SA groups. There was no significant difference in the 5year OS and DFS between stage II CRC patients in the ACT and SA groups (5-year OS, $81.4 \%$ vs. $78.7 \%, P=$ 0.738 , Fig. $7 \mathrm{a}$; and 5 -year DFS, $79.1 \%$ vs. $77.9 \%, P=$ 0.896 , Fig. $7 \mathrm{~b})$. When LVI+ patients were analyzed, however, ACT group patients had significantly higher 5 -year OS and DFS rates than the SA group (5-year OS, $66.7 \%$ vs. $40.9 \%, P=0.004$, Fig. $7 \mathrm{c}$; and 5 -year DFS, $64.1 \%$ vs. $36.3 \%, P=0.002$, Fig. $7 \mathrm{~d}$ ).

\section{Discussion}

CRC has become a major public health issue worldwide, with 1.4 million new cases and 0.7 million deaths each year [20]. Curative surgery with or without chemotherapy and radiotherapy is the mainstay of treatment for CRC [21]. ACT is recommended for stages III and IV CRC patients [4]. It has been reported that ACT improves OS in stage III patients [22]; however, the benefit of ACT in stage II CRC patients is controversial.

The 8th TNM staging system remains the most important prognostic indicator for CRC patients [8]. For pN stage patients, at least 12 ELNs are recommended to avoid false-negative prognostication; however, it is unavoidable that some cases have $<12$ ELNs, which may interfere with the nodal classification and even influence prognosis. LVI has been reported to occur in $10-89.5 \%$ of CRC patients [23], which is also considered to increase the risk for micrometastases in localized cancer
[24]. Thus, in this study, we focused on stage II LVI+ patients with $<12$ ELNs.

As a common histopathologic finding, LVI serves as a prognostic risk factor in many carcinomas $[23,25$, 26]. In this study, the LVI+ rate was $34.2 \%$ among all CRC patients and $37.7 \%$ of stage II CRC patients, which is in agreement with previous studies [20]. Differences in the LVI+ rate might reflect the diagnostic technique used and the number of patients in various studies [27]. In our 100 stage II LVI+ patients, LVI was significantly correlated with $\mathrm{pT}$ stage, degree of differentiation, tumor stage, serum CEA and CA19-9 levels, KRAS status, TB, and PNI. Similar to our results, Lim et al. [23] reported an association between LVI and more advanced $\mathrm{T}$ and $\mathrm{N}$ categories, higher pre-CEA levels, and worse tumor grade. Al-Sukhni et al. [28] also concluded that LVI is related to several factors in patients with advanced CRC, including larger size, more advanced T stage, LN involvement, and distant metastasis. Zhong et al. [1] also showed that LVI is significantly associated with an increased CEA level, increased tumor differentiation, and advanced tumor stage. These studies all support our results. Thus, it has been suggested that the presence of LVI should serve as an indicator of extending the resection area [29].

Survival analyses were conducted in this study. The 5 -year OS and DFS rates in stage II LVI+ patients were significantly less than LVI- patients. We even found that stage II LVI+ patients with $<12$ ELNs had 
Table 3 Univariate and multivariate analysis of prognostic factors for stage II patients with <12 ELNs. We analyzed the prognostic factors for those patients. As listed in Table 3, univariate analysis showed that LVI, pT-stage, degree of differentiation, serum CEA and CA19-9 levels, perineural invasion, tumor budding, and KRAS status were significant prognostic factors for those patients

\begin{tabular}{|c|c|c|c|c|c|c|}
\hline \multirow[t]{2}{*}{ Parameters } & \multirow{2}{*}{$\begin{array}{l}\text { Patients } \\
n(\%)\end{array}$} & \multirow{2}{*}{$\begin{array}{l}\text { 5-year } \\
\text { OS (\%) }\end{array}$} & \multicolumn{2}{|l|}{ Univariate analysis } & \multicolumn{2}{|c|}{ Multivariate analysis } \\
\hline & & & HR (95\% Cl) & $P$ & HR (95\% Cl) & $P$ \\
\hline Sex & & & & 0.675 & & \\
\hline Female & 53 & 67.9 & & & & \\
\hline Male & 55 & 69.1 & & & & \\
\hline Age (years) & & & & 0.255 & & \\
\hline$\leq 65$ & 54 & 64.8 & & & & \\
\hline$>65$ & 54 & 72.2 & & & & \\
\hline Tumor site & & & & 0.384 & & \\
\hline Colon & 57 & 63.2 & & & & \\
\hline Rectum & 51 & 68.6 & & & & \\
\hline Tumor size (cm) & & & & 0.078 & & \\
\hline$\leq 4$ & 60 & 61.7 & & & & \\
\hline$>4$ & 48 & 77.1 & & & & \\
\hline Lymphovascular invasion & & & $2.313(1.897-4.562)$ & 0.016 & $2.313(1.897-4.562)$ & 0.033 \\
\hline Positive & 48 & 60.4 & & & & \\
\hline Negative & 60 & 75.0 & & & & \\
\hline T-stage & & & $2.358(1.767-3.897)$ & $<0.001$ & $2.358(1.767-3.897)$ & 0.001 \\
\hline T3 & 59 & 81.4 & & & & \\
\hline T4 & 49 & 53.1 & & & & \\
\hline Differentiation degree & & & $1.879(1.223-4.563)$ & 0.002 & $1.879(1.223-4.563)$ & 0.044 \\
\hline Well & 53 & 77.4 & & & & \\
\hline Moderate & 53 & 62.3 & & & & \\
\hline Poor & 2 & 0 & & & & \\
\hline CEA & & & $3.011(1.997-4.967)$ & $<0.001$ & $3.011(1.997-4.967)$ & $<0.001$ \\
\hline$\leq 5 \mathrm{ng} / \mathrm{ml}$ & 61 & 78.7 & & & & \\
\hline$>5 \mathrm{ng} / \mathrm{ml}$ & 47 & 55.3 & & & & \\
\hline CA19-9 & & & 1.935 (1.156-3.768) & 0.001 & 1.935 (1.156-3.768) & 0.015 \\
\hline$\leq 37 \mathrm{U} / \mathrm{ml}$ & 69 & 75.4 & & & & \\
\hline$>37 \mathrm{U} / \mathrm{ml}$ & 39 & 56.4 & & & & \\
\hline KRAS status & & & $2.430(1.238-4.770)$ & 0.010 & $2.277(1.115-4.653)$ & 0.013 \\
\hline Wild type & 68 & 76.5 & & & & \\
\hline Mutant type & 40 & 55.0 & & & & \\
\hline PNI & & & $2.848(1.386-5.852)$ & 0.004 & $2.837(1.090-5.385)$ & 0.003 \\
\hline Positive & 19 & 42.1 & & & & \\
\hline Negative & 89 & 74.2 & & & & \\
\hline Tumor budding & & & $2.480(1.251-4.916)$ & 0.009 & $2.472(1.099-5.559)$ & 0.007 \\
\hline Low & 80 & 75.0 & & & & \\
\hline High & 28 & 50.0 & & & & \\
\hline
\end{tabular}

CRC Colorectal cancer; LN Lymph nodes; ELNs Examined lymph nodes; OS Overall survival; PNI Perineural invasion; TB Tumor budding 
Table 4 Comparison of the performance of the 8th edition of the TNM Staging System alone and the 8th edition of the TNM Staging System combined with LVI. We combined the LVI with the 8th TNM staging system. A comparison was made to estimate the prognostic value between the new system and the 8th TNM staging system. As listed in Table 4, the 8th TNM staging system combined with LVI had a higher C-index than the 8th TNM staging system alone (C-index, 0.895 vs. 0.833), which indicates a better prognostic value for CRC patients

\begin{tabular}{|c|c|c|c|c|c|}
\hline Classification & Stage & $n$ & 5-year OS (\%) & C-index & $95 \% \mathrm{Cl}$ \\
\hline \multirow[t]{3}{*}{ 8th TNM } & I & 173 & 90.2 & 0.833 & $0.785-0.889$ \\
\hline & $\|$ & 409 & 72.5 & & \\
\hline & III & 838 & 56.2 & & \\
\hline \multirow[t]{3}{*}{ 8th TNM+LVI } & I & 173 & 90.2 & 0.895 & $0.812-0.924$ \\
\hline & $\|$ & 361 & 74.2 & & \\
\hline & III & 886 & 56.9 & & \\
\hline
\end{tabular}

C-index Harrell's concordance index; LVI Lymphovascular invasion; OS Overall survival; $\mathrm{Cl}$ Confidence interval

a poor 5-year OS rate that was similar to stage III CRC patients. Multivariate analysis showed that LVI, KRAS status, TB, and PNI were significant prognostic factors for stage II CRC patients. Similar to our conclusion, it has been shown that LVI is an independent poor prognostic factor for survival among CRC patients [30]. Huh et al. [31] also reported that N0 stage CRC patients, especially stage II, may benefit most from the presence of LVI because these patients may have a superior response to ACT. The current metaanalysis shows that mutations in the KRAS gene appear to be associated with OS in CRC patients [32]. However, another study found that KRAS and BRAF mutations are independent poor prognostic factors for the OS of stage IV tumors rather than stages I-III tumors [33]. Jang et al. [34] concluded that KRAS mutations are significantly associated with high-grade TB; furthermore, tumors with KRAS mutations in exons 3 and 4 tended to have LVI and PNI. Marx et al. [35] concluded that higher TB status is related to higher tumor grade and stage, positive lymph nodes, and LVI; similar to our conclusion, it has been shown that $\mathrm{TB}$ is an independent poor prognostic factor for survival among CRC patients. Al-Sukhni et al. [28] reported an association between LVI, PNI, and advanced CRC and found that PNI is an independent poor prognostic marker for survival in CRC. Skancke et al. [4] also showed that LVI and PNI have an adverse effect on the survival of patients with stage II colon cancer. When LVI and PNI are present, ACT may have a protective effect.

To explore the benefit from ACT, we focused on the survival of ACT patients with or without LVI. Our results showed that ACT improved the 5-year OS and DFS rates in $\mathrm{LVI}+$ patients. Several studies have reported that ACT is beneficial for stage II CRC patients [36, 37]. Similar conclusions were reported by Skancke et al. [4], who demonstrated that CRC patients with high-risk factors, including LVI, can benefit from ACT. Arakawa et al. [38] reported that a significant prognostic benefit is achieved after ACT for stage IIb/c CRC patients. Lin et al. [39] enrolled 1039 stage II CRC patients and concluded that ACT improves the DFS rate in high-risk stage II CRC patients.

It has been reported that the improvement in OS and DFS rates with ACT did not differ significantly between high- and low-risk stage II CRC patients [22]. Fu et al. [3] suggested that the value of ACT in stage II colon cancer is much less than previously thought; de-escalating chemotherapy for these patients is necessary. Booth et al. [40] reported that ACT is not related to improved survival for stage II CRC patients with high-risk factors. Although there exist some differences in opinions, we still believe ACT is beneficial for LVI+ patients. The current therapy strategies for N0 stage CRC patients do not directly account for LVI.

To further explain the prognostic value of LVI in CRC patients, we combined LVI with the 8th TNM staging system, which had a better predictive efficacy than the 8th TNM staging system alone. Incorporating the negative impact of LVI into the staging system of CRC may predict the prognosis with greater precision and further establish a more reasonable therapeutic strategy for stage II CRC patients.

This study had some limitations. This was a retrospective study from a single center, and the sample size was not sufficiently large, which may have led to selection bias. A multicenter collaborative study with a large sample size may overcome this issue. In addition, we only focused on the phenomenon and the consequences resulting from LVI; thus, it is necessary for us to explore the genetic mechanism underlying LVI, which may provide novel biomarkers and establish new tumor therapeutic strategies for CRC.

\section{Conclusions}

LVI, TB, and PNI are independent prognostic risk factors for stage II CRC patients. Stage II CRC with inadequate ELNs and LVI+ could benefit from adjuvant chemotherapy. The inclusion of LVI can improve the predictive accuracy of the 8th TNM staging system for CRC prognosis. ACT in stage II CRC patients with LVI+ is beneficial for survival. 


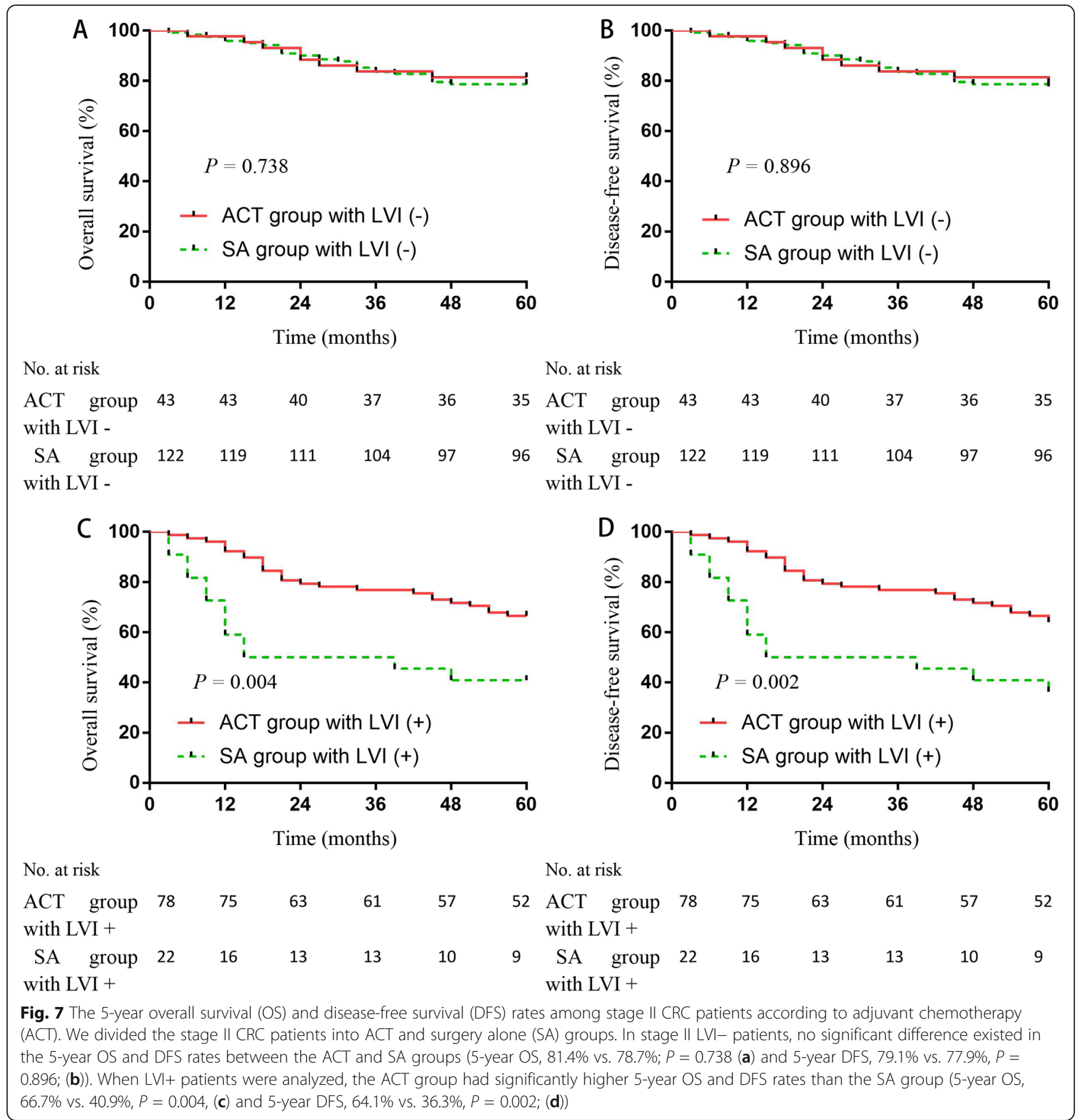

\section{Abbreviations}

LVI: Lymphovascular invasion; CRC: Colorectal cancer; ELNs: Examination of lymph nodes; ACT: Adjuvant chemotherapy; PNI: Perineural invasion;

TB: Tumor budding; OS: Overall survival; DFS: Disease-free survival;

LNs: Lymph nodes; TNM: Tumor-node-metastasis

\section{Acknowledgements}

Not applicable.

\section{Statement}

All methods in this article are implemented in accordance with relevant guidelines and regulations.

\section{Disclosures}

The authors have no financial conflict of interest.

Authors' contributions

ZG and HC wrote the manuscript and analyzed data. QW and XX collected the data of patients. YW and QL assisted ZG and HC to complete the work. YW funded the study. The authors read and approved the final manuscript.

Funding

The present study was supported by the major science and technology project of Changzhou Commission of Health (grant no. ZD201905). 


\section{Availability of data and materials}

The datasets used and/or analyzed during the current study are available from the corresponding author on reasonable request.

\section{Declarations}

\section{Ethics approval and consent to participate}

This study was approved by the Ethics Committee of The Third Affiliated Hospital of Soochow University.

\section{Consent for publication}

Informed consent was obtained from all patients.

\section{Competing interests}

The authors declare that they have no competing interests.

\section{Author details}

'Department of General Surgery, The Third Affiliated Hospital of Soochow University and The First People's Hospital of Changzhou, 185 Juqian Street, Changzhou 213000, Jiangsu, China. ${ }^{2}$ Department of General Surgery, Traditional Chinese Medicine Hospital of Kunshan, Suzhou 215000, Jiangsu, China.

\section{Received: 14 January 2021 Accepted: 1 April 2021}

\section{Published online: 18 April 2021}

\section{References}

1. Zhong JW, Yang SX, Chen RP, Zhou YH, Ye MS, Miao L, et al. Prognostic value of lymphovascular invasion in patients with stage III colorectal cancer: a retrospective study. Med Sci Monit. 2019;25:6043-50. https://doi.org/10.12 659/MSM.918133.

2. Cao H, Wang Q, Gao Z, Xu X, Lu Q, Wu Y. Clinical value of detecting IQGA $\mathrm{P} 3, \mathrm{~B} 7-\mathrm{H} 4$ and cyclooxygenase-2 in the diagnosis and prognostic evaluation of colorectal cancer. Cancer Cell Int. 2019;19(1):163. https://doi.org/10.1186/ s12935-019-0881-3.

3. Fu J, Wu L, Ge C, et al. De-escalating chemotherapy for stage II colon cancer? Therap Adv Gastroenterol. 2019;12:1756284819867553.

4. Skancke M, Arnott SM, Amdur RL, Siegel RS, Obias VJ, Umapathi BA. Lymphovascular invasion and perineural invasion negatively impact overall survival for stage II adenocarcinoma of the colon. Dis Colon Rectum. 2019; 62(2):181-8. https://doi.org/10.1097/DCR.0000000000001258.

5. Meyers BM, Cosby R, Quereshy F, Jonker D. Adjuvant chemotherapy for stage II and III colon cancer following complete resection: a Cancer Care Ontario systematic review. Clin Oncol (R Coll Radiol). 2017;29(7):459-65. https://doi.org/10.1016/j.clon.2017.03.001.

6. Benson AB, Venook AP, Al-Hawary MM, et al. NCCN guidelines insights: colon cancer, Version 2.2018. J Natl Compr Canc Netw. 2018;16(4):359-69. https://doi.org/10.6004/jnccn.2018.0021.

7. Betge J, Harbaum L, Pollheimer MJ, Lindtner RA, Kornprat P, Ebert MP, et al. Lymph node retrieval in colorectal cancer: determining factors and prognostic significance. Int J Colorectal Dis. 2017;32(7):991-8. https://doi. org/10.1007/s00384-017-2778-8.

8. Kim MJ, Jeong SY, Choi SJ, Ryoo SB, Park JW, Park KJ, et al. Survival paradox between stage IIB/C (T4N0) and stage IIIA (T1-2N1) colon cancer. Ann Surg Oncol. 2015;22(2):505-12. https://doi.org/10.1245/s10434-014-3982-1.

9. Hamy AS, Lam GT, Laas E, Darrigues L, Balezeau T, Guerin J, et al. Lymphovascular invasion after neoadjuvant chemotherapy is strongly associated with poor prognosis in breast carcinoma. Breast Cancer Res Treat. 2018;169(2):295-304. https://doi.org/10.1007/s10549-017-4610-0.

10. Mathieu R, Lucca I, Roupret M, Briganti A, Shariat SF. The prognostic role of lymphovascular invasion in urothelial carcinoma of the bladder. Nat Rev Urol. 2016;13(8):471-9. https://doi.org/10.1038/nrurol.2016.126.

11. Lee JH, Kim MG, Jung MS, Kwon SJ. Prognostic significance of lymphovascular invasion in node-negative gastric cancer. World J Surg. 2015;39(3):732-9. https://doi.org/10.1007/s00268-014-2846-y.

12. van Wyk HC, Roxburgh CS, Horgan PG, Foulis AF, McMillan DC. The detection and role of lymphatic and blood vessel invasion in predicting survival in patients with node negative operable primary colorectal cancer. Crit Rev Oncol Hematol. 2014;90(1):77-90.

13. Lugli A, Kirsch R, Ajioka Y, Bosman F, Cathomas G, Dawson H, et al. Recommendations for reporting tumor budding in colorectal cancer based on the International Tumor Budding Consensus Conference (ITBCC) 2016. Mod Pathol. 2017;30(9):1299-311. https://doi.org/10.1038/modpathol.2017.4 6.

14. Liebig C, Ayala G, Wilks JA, Berger DH, Albo D. Perineural invasion in cancer: a review of the literature. Cancer. 2009;115:3379-91.

15. Batsakis JG. Nerves and neurotropic carcinomas. Ann Otol Rhinol Laryngol. 1985:94:426-7.

16. Duraker N, Sisman S, Can G. The significance of perineural invasion as a prognostic factor in patients with gastric carcinoma. Surg Today. 2003;33(2): 95-100. https://doi.org/10.1007/s005950300020.

17. Law WL, Chu KW. Anterior resection for rectal cancer with mesorectal excision: a prospective evaluation of 622 patients. Ann Surg. 2004;240(2): 260-8. https://doi.org/10.1097/01.sla.0000133185.23514.32.

18. Ozaki H, Hiraoka T, Mizumoto R, Matsuno S, Matsumoto Y, Nakayama T, et al. The prognostic significance of lymph node metastasis and intrapancreatic perineural invasion in pancreatic cancer after curative resection. Surg Today. 1999;29(1):16-22. https://doi.org/10.1007/BF02482964.

19. Su CH, Tsay SH, Wu CC, Shyr YM, King KL, Lee CH, et al. Factors influencing postoperative morbidity, mortality, and survival after resection for hilar cholangiocarcinoma. Ann Surg. 1996;223(4):384-94. https://doi.org/10.1097/ 00000658-199604000-00007.

20. Jiang HH, Zhang ZY, Wang XY, Tang $X$, Liu HL, Wang AL, et al. Prognostic significance of lymphovascular invasion in colorectal cancer and its association with genomic alterations. World J Gastroenterol. 2019;25(20): 2489-502. https://doi.org/10.3748/wjg.v25.i20.2489.

21. Moccia F, Tolone S, Allaria A, Napolitano V, Rosa D'A, llaria F, et al. Lymph node ratio versus TNM system as prognostic factor in colorectal cancer staging. A single center experience. Open Med (Wars). 2019;14(1):523-31. https://doi.org/10.1515/med-2019-0058.

22. Jalaeikhoo $H$, Zokaasadi M, Khajeh-Mehrizi A, et al. Effectiveness of adjuvant chemotherapy in patients with Stage II colorectal cancer: a multicenter retrospective study. J Res Med Sci. 2019:24:39.

23. Lim SB, Yu CS, Jang SJ, Kim TW, Kim JH, Kim JC. Prognostic significance of lymphovascular invasion in sporadic colorectal cancer. Dis Colon Rectum. 2010;53(4):377-84. https://doi.org/10.1007/DCR.0b013e3181cf8ae5.

24. Barresi V, Reggiani Bonetti L, Vitarelli E, Di Gregorio C, Ponz de Leon M, Barresi G. Immunohistochemical assessment of lymphovascular invasion in stage I colorectal carcinoma: prognostic relevance and correlation with nodal micrometastases. Am J Surg Pathol. 2012;36(1):66-72. https://doi. org/10.1097/PAS.0b013e31822d3008.

25. Rakha EA, Martin S, Lee AH, et al. The prognostic significance of lymphovascular invasion in invasive breast carcinoma. Cancer. 2012;118(15): 3670-80. https://doi.org/10.1002/cncr.26711.

26. Higgins KA, Chino JP, Ready N, D'Amico TA, Berry MF, Sporn T, et al. Lymphovascular invasion in non-small-cell lung cancer: implications for staging and adjuvant therapy. J Thorac Oncol. 2012;7(7):1141-7. https://doi. org/10.1097/JTO.0b013e3182519a42.

27. Betge J, Pollheimer MJ, Lindtner RA, Kornprat P, Schlemmer A, Rehak P, et al. Intramural and extramural vascular invasion in colorectal cancer: prognostic significance and quality of pathology reporting. Cancer. 2012; 118(3):628-38. https://doi.org/10.1002/cncr.26310.

28. Al-Sukhni E, Attwood K, Gabriel EM, LeVea CM, Kanehira K, SJ N. Lymphovascular and perineural invasion are associated with poor prognostic features and outcomes in colorectal cancer: a retrospective cohort study. Int J Surg. 2017:37:42-9.

29. Choi JY, Jung SA, Shim KN, Cho WY, Keum B, Byeon JS, et al. Meta-analysis of predictive clinicopathologic factors for lymph node metastasis in patients with early colorectal carcinoma. J Korean Med Sci. 2015;30(4):398-406. https://doi.org/10.3346/jkms.2015.30.4.398.

30. Huh JW, Lee JH, Kim HR, Kim YJ. Prognostic significance of lymphovascular or perineural invasion in patients with locally advanced colorectal cancer. Am J Surg. 2013;206(5):758-63. https://doi.org/10.1016/j.amjsurg.2013.02.010.

31. Huh JW, Kim HR, YJ K. Prognostic value of perineural invasion in patients with stage II colorectal cancer. Ann Surg Oncol. 2010;17(8):2066-72.

32. Kwak MS, Cha JM, Yoon JY, Jeon JW, Shin HP, Chang HJ, et al. Prognostic value of KRAS codon 13 gene mutation for overall survival in colorectal cancer: direct and indirect comparison meta-analysis. Medicine (Baltimore). 2017;96(35):e7882. https://doi.org/10.1097/MD.0000000000007882.

33. Guo TA, Wu YC, Tan C, Jin YT, Sheng WQ, Cai SJ, et al. Clinicopathologic features and prognostic value of KRAS, NRAS and BRAF mutations and DNA mismatch repair status: a single-center retrospective study of 1,834 Chinese 
patients with stage I-IV colorectal cancer. Int J Cancer. 2019;145(6):1625-34. https://doi.org/10.1002/ijc.32489.

34. Jang SJ, Hong M, Shin MK, Kim BC, Shin HS, Yu E, et al. KRAS and PIK3CA mutations in colorectal adenocarcinomas correlate with aggressive histological features and behavior. Hum Pathol. 2017;65:21-30. https:/doi. org/10.1016/j.humpath.2017.01.010.

35. Marx AH, Mickler C, Sauter G, Simon R, Terracciano LM, Izbicki JR, et al. Highgrade intratumoral tumor budding is a predictor for lymphovascular invasion and adverse outcome in stage II colorectal cancer. Int J Colorectal Dis. 2020;35(2):259-68. https://doi.org/10.1007/s00384-019-03478-w.

36. Casadaban L, Rauscher G, Aklilu M, Villenes D, Freels S, Maker AV. Adjuvant chemotherapy is associated with improved survival in patients with stage II colon cancer. Cancer. 2016;122(21):3277-87. https://doi.org/10.1002/cncr.301 81.

37. Yun HR, Kim HC, Yun SH, Lee WY. Adjuvant chemotherapy increase survival and decrease recurrence in stage IIA colon cancer. Hepatogastroenterology. 2012;59(120):2466-71. https://doi.org/10.5754/hge10260.

38. Arakawa K, Kawai K, Tanaka T, Hata K, Sugihara K, Nozawa H. Prognostic impact of interhospital variation in adjuvant chemotherapy for patients with stage II/III colorectal cancer: a nationwide study. Colorectal Dis. 2018;20(7): 0162-0172. https://doi.org/10.1111/codi.14260.

39. Lin HH, Chang YY, Lin JK, Jiang JK, Lin CC, Lan YT, et al. The role of adjuvant chemotherapy in stage II colorectal cancer patients. Int J Colorectal Dis. 2014;29(10):1237-43. https://doi.org/10.1007/s00384-014-1943-6.

40. Booth CM, Nanji S, Wei X, Peng Y, Biagi JJ, Hanna TP, et al. Adjuvant chemotherapy for stage II colon cancer: practice patterns and effectiveness in the general population. Clin Oncol (R Coll Radiol). 2017;29(1):e29-38. https://doi.org/10.1016/j.clon.2016.09.001.

\section{Publisher's Note}

Springer Nature remains neutral with regard to jurisdictional claims in published maps and institutional affiliations.

Ready to submit your research? Choose BMC and benefit from:

- fast, convenient online submission

- thorough peer review by experienced researchers in your field

- rapid publication on acceptance

- support for research data, including large and complex data types

- gold Open Access which fosters wider collaboration and increased citations

- maximum visibility for your research: over $100 \mathrm{M}$ website views per year

At $\mathrm{BMC}$, research is always in progress.

Learn more biomedcentral.com/submissions 